\title{
Design, simulation and experiments on a new flat plate sandwich heat exchanger
}

\author{
S.F. Smeding \\ N. Bakker \\ R. de Boer
}




\title{
Acknowledgement/Preface
}

This research is part of the EOS-LT programme, financially supported by the Dutch Ministry of Economics Affairs and managed by Senter Novem.

\begin{abstract}
A sandwich plate heat exchanger has been designed for application in a high temperature solid sorption heat pump. The heat exchanger consists of two metal sheets that are brazed together with a metal wire mesh in between. This results in a light-weight construction with favourable heat transfer properties and sufficient mechanical strength to resist cyclic pressure variations. The flow distribution in a circular sandwich plate heat exchanger was determined experimentally as well as the average internal heat transfer rate. The results of these experiments were in good agreement with results of simulations that determined the local and average flow, temperature and heat transfer. Finite element calculations were done to select plate thickness and wire mesh dimensions of a sandwich plate heat exchanger to be applied in solid sorption heat pump where it should resist up to hundred thousand load cycles.
\end{abstract}




\section{Contents}

List of tables $\quad 4$

List of figures 4

Nomenclature $\quad 4$

1. Introduction 5

2. Design and construction 6

3. Mechanical and thermal calculations 8

3.1 Evaluation of the tensile strength 8

3.2 Heat transfer model for the local heat transfer 10

4. Heat transfer experiments and results 12

\begin{tabular}{ll}
4.1 & Visualisation of flow distribution \\
\hline & 12
\end{tabular}

4.2 Heat transfer measurement 13

5. Sandwich plate heat exchanger applications 16

6. Conclusions 17 


\section{List of tables}

Table 3.1 Allowable stress range versus number of cycles to failure

\section{List of figures}

Figure 2.1 Drawing of a cross section of the sandwich plate structure. The heat exchanger consists of two plates with a wire mesh brazed on the contact points to the plates.

Figure 2.2 Design drawings of the sandwich plate - cross section of the sandwich plate + metal foam (a). Detail of the heat transfer channel (b). A single chemical heat pump reactor, consisting of six heat exchanger plates +foam, a diffuser for the entry and exit of the heat transfer medium and a shell (c)

Figure 3.1 The area of the crack of the braze after elasto-plastic failure ................................... 8

Figure 3.2 Definition and equations for design stress pmesh ................................................... 9

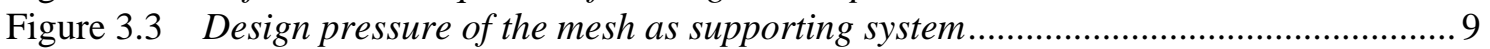

Figure 3.4 Definition and equations for design stress Pplate ................................................... 9

Figure 3.5 Design pressure of the plate as supporting system .............................................. 9

Figure 3.6 Distribution of the equivalent stress for the plate (A), the mesh (B) and the

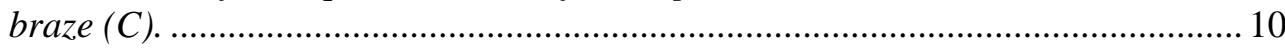

Figure 3.7 Scheme of the model to calculate flow, heat transfer and pressure drop. The definition of the grid is in cylindrical coordinates. The flow enters the grid in radial direction in cell $A 1$ and leaves the grid at cell A6.

Figure 4.1 Flow pattern at $t=1.4 \mathrm{sec}$ without wire mesh. The short-circuit time is 1.6 seconds $(\zeta \cong 0.3)$.......

Figure 4.2 Flow pattern at $t=1.4 \mathrm{sec}$ with wire mesh under an angle of $45^{\circ}$. The shortcircuit time is 1.2 seconds $\zeta \cong 0.27$ ).

Figure 4.3 Image analysis of the measured flow pattern without flow distributor. The shortcircuit time is 1.2 seconds ( $\zeta \cong 0.25$ ), with large differences in velocity.................. 13

Figure 4.4 Image analysis of the measured flow pattern with four flow distributors. The short-circuit time is \pm 3 seconds $(\zeta \cong 0.75)$. The flow distribution is quite good. .... 13

Figure 4.5 Measurement of hA-value (coefficient of overall heat transfer $x$ heat transfer area) as a function of the flow. Medium is thermal oil Calflo LT with a temperature between $40-90^{\circ} \mathrm{C}$. Heat transfer area of sandwich plate heat exchanger $=0.4 \mathrm{~m}^{2}$.

Figure 4.6 Comparison of the measured values and the simulated values for the sandwich plate of thermal power just after switching from 40 to $90^{\circ} \mathrm{C}$ (heating) and 90 to $40^{\circ} \mathrm{C}$ (cooling). The medium is thermal oil Calflo LT, measurement in the vacuum vessel.

Figure 4.7 Measurement of hA-values as function of the flow. Medium is water with a temperature between $90-40^{\circ} \mathrm{C}$. Heat transfer area of the sandwich plate heat exchanger is $0.4 \mathrm{~m}^{2}$......

\section{Nomenclature}

$\mathrm{N} \quad$ Allowable number of stress cycles

$[-]$

$\zeta \quad$ Volume utilisation factor 


\section{Introduction}

A High Temperature Chemical Heat Pump (HTCHP) is in principle capable of realising temperature lifts in excess of $100^{\circ} \mathrm{C}$. This makes it an interesting system able to upgrade the temperature of a waste heat source towards a temperature where part of the waste heat can be re-used again. The working principle of the HTCHP that is being developed is based on the reversible absorption and desorption of a vapour in two different salts. The absorption of vapour is an exothermic effect releasing heat and desorption of vapour an endothermic effect consuming heat (Haije 2002).

Waste heat $\left(100-150^{\circ} \mathrm{C}\right)$ is used to produce vapour by decomposition of the low temperature salt. Subsequent absorption of this vapour by the high temperature salt produces heat at a high temperature level $\left(150-250^{\circ} \mathrm{C}\right)$. This process continues until all vapour is liberated from the low temperature salt. In this stage the system has to be recharged again. Feeding waste heat to the high temperature salt and simultaneously cooling the low temperature salt to ambient temperature achieves this. This process results in all vapour to be absorbed again in the low temperature salt so that the cycle can recommence. By using a duplicate set of reactors, this batch process can be made semi-continuous.

The performance of this system depends to a great extent on the rates of heat and mass transfer (Lambert 2005). Since the poor heat conduction of a solid salt, a large heat transfer area is necessary. In addition the vapour transport through the salt bed should not become rate limiting. A heat exchanger with plate geometry with a thin layer of salt attached to the surface could well satisfy to achieve a compact system. However, the current commercially available plate heat exchangers lack space to accommodate a sufficient amount of salt as well as a means for transport of the vapour phase. Therefore a novel sandwich plate heat exchanger concept is developed that has favourable properties for use in a chemical heat pump system.

A flat plate sandwich structure consists in general of two thin (metal) plates with a support structure in between. Lu (2005) described eight types of structures: woven textile; square honeycomb; pyramidal truss; corrugated sheet; hollow tube; diamond prismatic cell; heat pipes and kagome truss. The structures were characterised by three dimensionless parameters: the Nusselt number, the friction factor and the Reynolds number. The flat plate heat exchanger of the present study uses a structure of a single layer of double scrimp screens (welded wire mesh) that is brazed together with the thin plates. The new concept differs a great deal from commercial plate heat exchangers as to heat transfer and construction. Alfa Laval and Vahterus [2x ref www....] use corrugates plates that are stacked so as to form one heat exchanger. The flow in this kind of heat exchangers is determined by the corrugation pattern, while the flow in a flat sandwich plate heat exchanger is determined by the choice of the support structure.

This paper describes the design and construction of the sandwich plate heat exchanger designed for application in a chemical heat pump. The applicable ranges for pressure and temperature are determined by tensile strength calculations. A simulation model is used to predict heat transfer rates of the sandwich plate. Results of this model are verified with measurements of flow distribution and heat transfer. Finally alternative applications of the sandwich plate heat exchanger concept are described. 


\section{Design and construction}

The sandwich structure consists of two thin flat plates with a wire mesh between (see Figure 2.1). The junctions of the wire mesh are vacuum brazed to both plates. The construction can resist high-pressure differences from inside to outside due to the proportional distribution of the junctions. The heat transfer medium flows through the open space of the wire mesh and transfers the heat to the area of the wire mesh and the wall. Especially for laminar flow conditions a good heat transfer is achieved through the continuous mixing up of the flow and forced disturbance of boundary layers. The secondary side (outside) of the heat exchanger surface is intended to be in close contact with the salt. Surface enlarging structures, such as a wire mesh, metal fins or foam can be applied to further increase the heat transfer at the secondary side.

For the development of a test-rig of a chemical heat pump a circular sandwich plate was chosen. The inlet and outlet channel are located in the centre in the form of a semi-circle (Figure 2.2a and 2.2b). The heat transfer medium flows from the channel to the space between the plates through a small gap. Flow conductors are placed inside the plates to distribute the flow evenly over the whole heat transfer area. A metal foam is brazed on the outside surface to enhance the effective conduction of heat to the salt. After brazing of the plates the salt mass is inserted as a porous medium inside and attached to the metal foam. Gaskets are used to assemble the brazed plates to a fluid tight stack (Figure 2.2c). A pull bar through the central opening clenches the stack together.

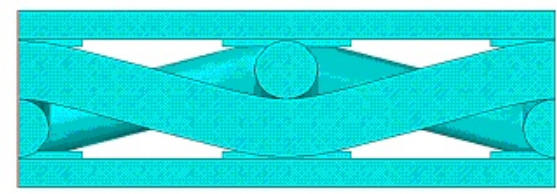

Figure 2.1 Drawing of a cross section of the sandwich plate structure. The heat exchanger consists of two plates with a wire mesh brazed on the contact points to the plates.

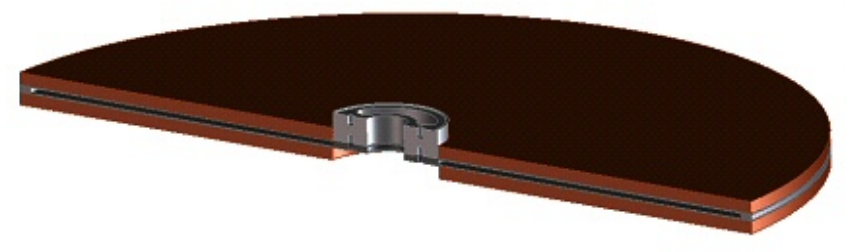

a

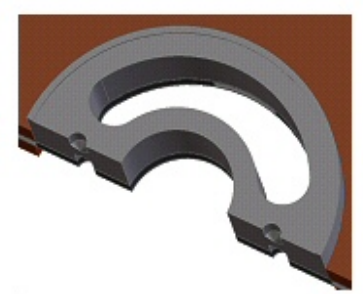

b

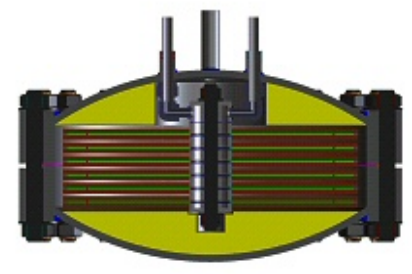

C

Figure 2.2 Design drawings of the sandwich plate - cross section of the sandwich plate + metal foam (a). Detail of the heat transfer channel (b). A single chemical heat pump reactor, consisting of six heat exchanger plates +foam, a diffuser for the entry and exit of the heat transfer medium and a shell (c)

A HTCWP requires a heat exchanger with the qualities of a long lifetime and an excellent heat transfer combined with low-pressure loss and no fouling. During the technical lifetime the number of temperature and pressure cycles is in the range of one hundred thousand. The temperature range is between 20 and 250 degrees Celsius. The pressure range inside the plate is maintained constant at a level between 1 and 40 barg and at the outside of the plate the pressure changes every cycle from 0.1 to 20 barg. 
The heat exchanger construction is especially load on a bow tension. The wire mesh locally supports the thin-walled plate. Through the combination of the plate and the mesh, the construction is considered as an orthotropic stiff plate. The dimensions of such a construction can be increased within the plane without changing the strength, the stiffness or the deformation.

For the selection of the optimum combination of plate thickness and wire mesh, 45 different meshes and 17 types of plates, all commercially available in stainless steel quality, are considered. For the chemical heat pump application the optimum amongst the 765 different plate and wire mesh combinations is the assembly with the lowest mass able to resist the specified pressure difference. The calculation method is described in the next section. 


\section{Mechanical and thermal calculations}

\subsection{Evaluation of the tensile strength}

The constructive components of the sandwich heat exchanger are evaluated for mechanical stiffness, strength and the number of load cycles to failure. During operational conditions, the heat exchanger experiences internal pressure loading at elevated temperature. The materials used are all stainless steel with the specification SA-182 F316L (ASME, 2001a). The static design stress is dependent on the temperature of the metal (see Table 3.1).

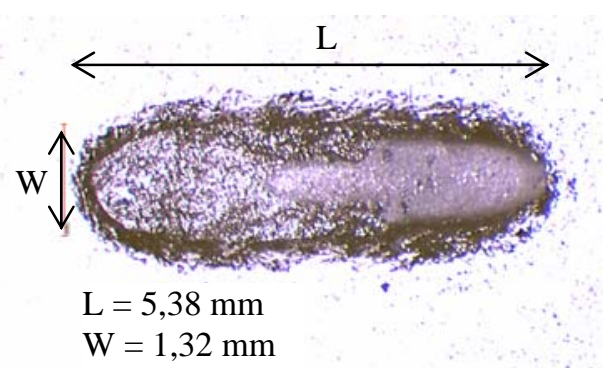

Figure 3.1 The area of the crack of the braze after elasto-plastic failure

Table 3.1 Allowable stress range versus number of cycles to failure

\begin{tabular}{cccccc}
$\begin{array}{c}\text { Temperature of } \\
\text { metal }\end{array}$ & $\begin{array}{c}\text { Allowable } \\
\text { design stress }\end{array}$ & \multicolumn{2}{c}{$\begin{array}{c}\text { Elastic material behaviour } \\
\text { (maximum Stress Range is } \\
\text { equal to twice the yield stress) }\end{array}$} & $\begin{array}{c}\text { Elasto-plastic material behaviour } \\
\text { (maximum stress range at } \\
10^{5} \text { the number of stress cycles) }\end{array}$ \\
\hline \multicolumn{7}{c}{ Stress cycles } & $\begin{array}{c}\text { Allowable } \\
\text { number of } \\
\text { stress cycles }\end{array}$ & Stress cycles & $\begin{array}{c}\text { Allowable } \\
\text { number of stress } \\
\text { cycles }\end{array}$ \\
$\mathrm{T}-\left[{ }^{\circ} \mathrm{C}\right]$ & $\sigma_{\mathrm{m}}\left[\mathrm{N} / \mathrm{mm}^{2}\right]$ & $\sigma_{\mathrm{R}}\left[\mathrm{N} / \mathrm{mm}^{2}\right]$ & $\mathrm{N}$ & $\sigma_{\mathrm{R}}\left[\mathrm{N} / \mathrm{mm}^{2}\right]$ & $\mathrm{N}$ \\
20 & 115 & 345 & $1,5010^{6}$ & 390 & $1,010^{5}$ \\
100 & 96 & 345 & $1,5010^{6}$ & 390 & $1,010^{5}$ \\
200 & 81 & 328 & $1,6810^{6}$ & 376 & $1,010^{5}$ \\
300 & 73 & 294 & $2,2510^{6}$ & 348 & $1,010^{5}$ \\
\hline
\end{tabular}

Fatigue limit stress range: $\sigma_{\mathrm{R} \max }=192 \mathrm{~N} / \mathrm{mm}^{2}$ at $10^{8}$ stress cycles.

With a tensile test the strength of the connection between the plate and the wire mesh is determined (see Figure 3.1). The results of this test are used for the design load (45 N), the failure load $(142 \mathrm{~N})$ and the maximum load at linear material behaviour $(77 \mathrm{~N})$. The fractured surface of the plate - wire mesh connection and the size of the fractured area is a measure for the load transfer from the wire to the plate. The length and the width of the brazed connection are considered in the models as respectively twice and once the diameter of the wire.

For 45 types of meshes with different dimensions the maximum allowed design stress $\mathrm{p}_{\text {mesh }}$ is calculated, which is related to the maximum allowable force $\mathrm{F}$ and the pitch (Figure 3.2). The metal temperature is fixed at $20^{\circ} \mathrm{C}$. The results of the Finite Elements Method (FEM) calculations are presented in Figure 3.3 as function of the ratio of the pitch and the wire diameter $\mathrm{D}_{\mathrm{w}}$. 
Similar to the mesh, the plate construction is calculated in FEM for 17 types of plates. The mesh supports the plate at the brazed joints. In Figure 3.4 the FEM model is described for the plate. The maximum allowed design stress is visualised in Figure 3.5 as function of the quotient of the square pitch and the plate thickness.

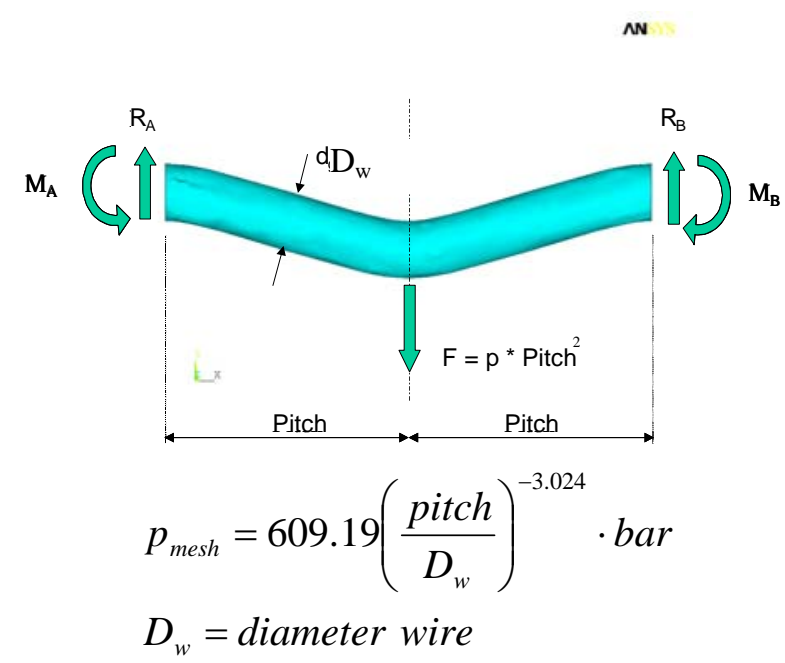

Figure 3.2 Definition and equations for design stress pmesh

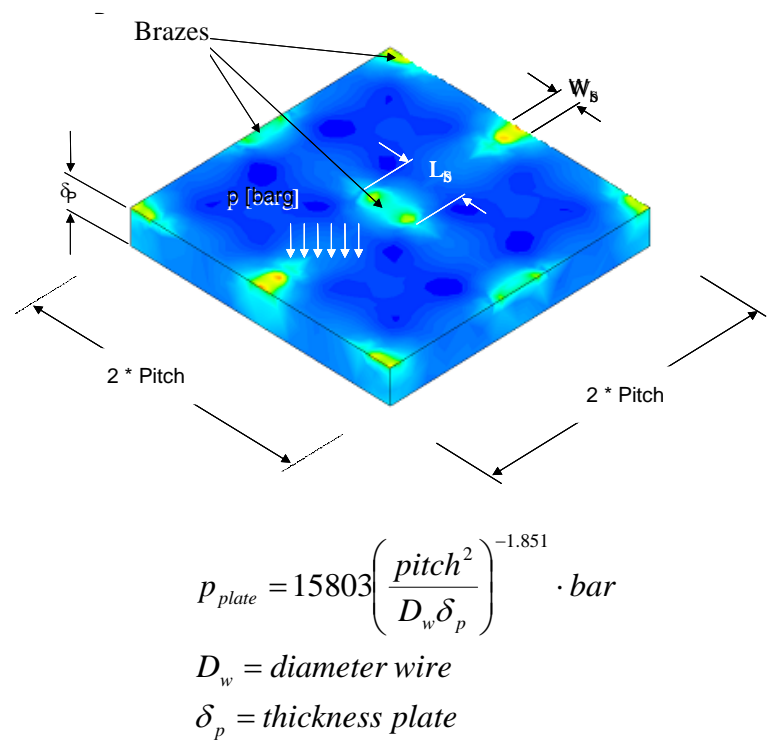

Figure 3.4 Definition and equations for design stress Pplate.

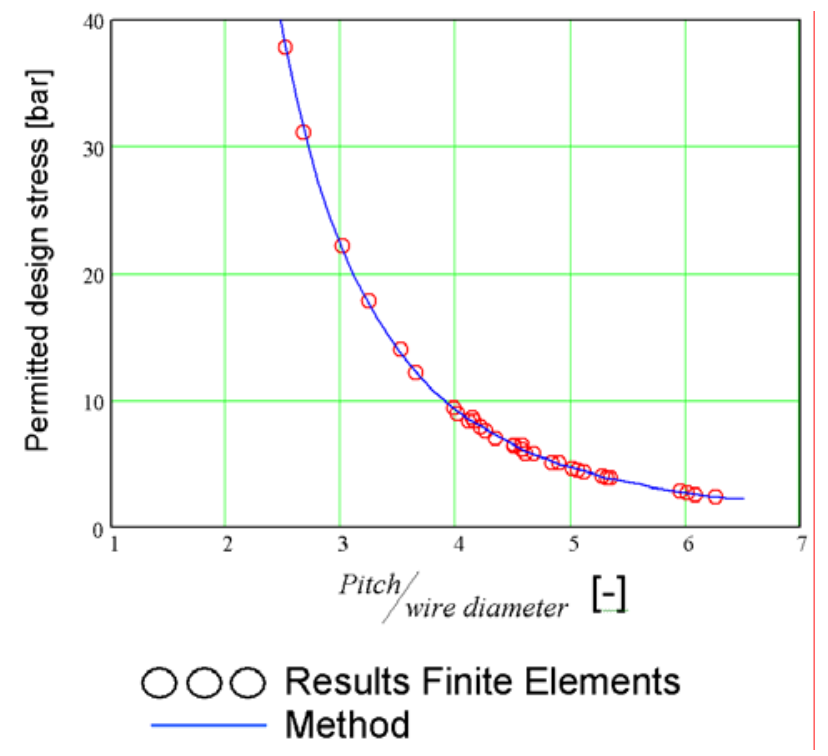

Figure 3.3 Design pressure of the mesh as supporting system

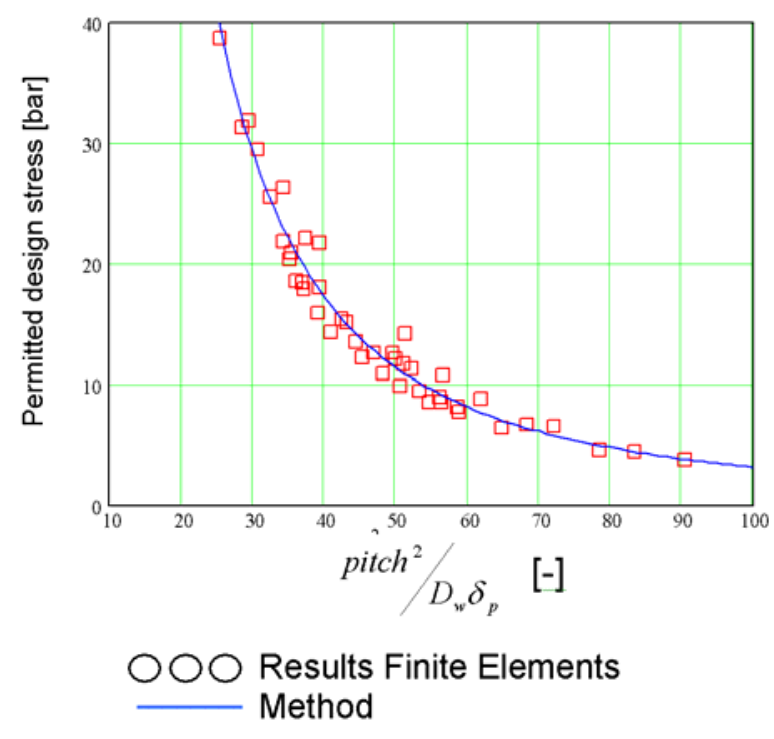

Figure 3.5 Design pressure of the plate as supporting system 
With a fracture mechanics analysis the lifetime to failure is calculated for the brazed area (Barsom - 1999). The temperature is changed in the range from 20 to $300^{\circ} \mathrm{C}$. The maximum stress of the tip of the crack is twice the yield stress of the steel. Based on the results of the calculations it was concluded that all the mesh-plate combinations fulfil the lifetime of failure $\left(>10^{5}\right.$ cycles) for the plate - braze connection in the case the initial defect is smaller as $0.125 \mathrm{~mm}$. An integral analysis of the heat exchanger leads to a much smaller size of the brazed connection. In combination with a thin solder foil of $0.05 \mathrm{~mm}$ the length of the brazed area is only $0.5 \mathrm{~mm}$ and this reduces the maximum permissible stress. Using the finite element method the forces, the deformations and the stresses of the construction are calculated. The stresses for evaluation are the membrane stress, the bending plus membrane stress and the peak stress. All the stresses have to fulfil the limits according the ASME code (2001). The equivalent stress is visualised in Figure 3.6 for the plate, the mesh and the solder junctions.

With a Simplified Elasto-Plastic Fatigue Analyses (ASME Code, 2001b) the number of cycles during the technical lifetime is calculated for a pre described design pressure. If the brazed area is smaller than twice the diameter of the wire, the technical lifetime can be lower as 100.000 cycles.

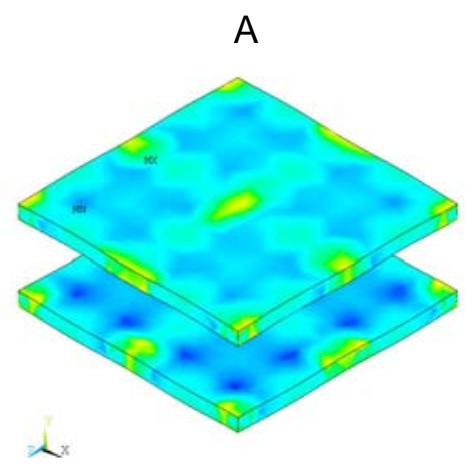

Plate thickness $=0.25 \mathrm{~mm}$

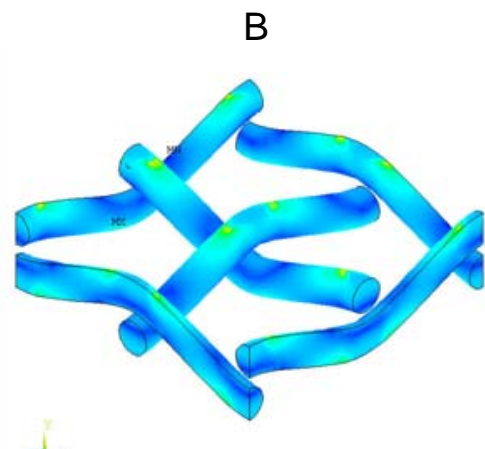

Wire diameter $=0.5 \mathrm{~mm}$ Pitch $=2.1 \mathrm{~mm}$

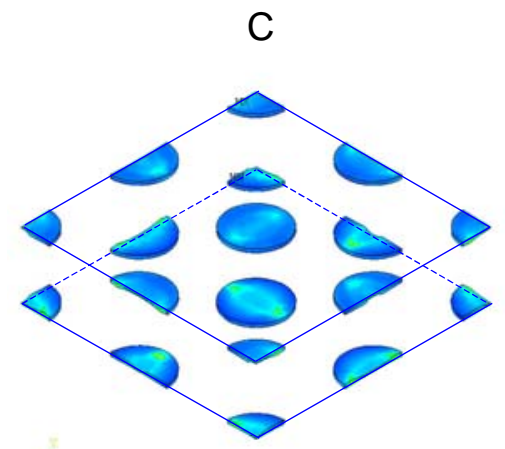

Length braze $=0.76 \mathrm{~mm}$ Width braze $=0.5 \mathrm{~mm}$

Figure 3.6 Distribution of the equivalent stress for the plate (A), the mesh (B) and the braze (C).

\subsection{Heat transfer model for the local heat transfer}

A simple model in Excel was developed to calculate the local flow direction and velocity, the local and average heat transfer and temperature distribution and the local pressure drop. The model uses a simple grid (24 cells) as defined in Figure 3.7. For reasons of symmetry, only half of the heat exchanger is simulated. Heat exchange takes place at both sides of the heat exchanger. The flow at inlet has a uniform velocity, the pressure at outlet is zero and at all other boundaries included the flow distributors a non slip conditions is used. The law of conservation of mass and the principle that the pressure loss is the same for every possible route of the medium are used to calculate the flow in each cell.

The convective heat transfer and the local pressure loss are a function of the Reynolds number. The physical properties (the dynamic viscosity and the density of the medium) are taken as a function of the temperature. For the measured and simulated range of flow velocity of the thermal oil the flow is laminar $(\operatorname{Re}<2300)$. The heat transfer from the medium to the wire of the mesh was not taking into account. Only the influence of a higher local flow velocity caused by the wire of the mesh was incorporated. It is important that the flow mixes up passing each wire of the mesh and develops after each wire again. Using an equation for combined entry length of parallel plates an approximated the value for the heat transfer is obtained. The correlation for the mean Nusselt number for a general duct of length $L$ is given by (Hewitt, 2002): 
$N u_{\text {lam }, L / D<20}=1.849 \cdot\left(\frac{\operatorname{Re} \operatorname{Pr}}{L / D_{h}}\right)^{1 / 3}$ for $\frac{\operatorname{Re} \operatorname{Pr}}{L / D_{h}}>10^{3}$

For parallel plates the hydraulic diameter is twice the plate spacing and for a rectangular channel:

$D_{h}=\frac{2 a b}{a+b} \quad$ where $a$ is the longer and $b$ the shorter side

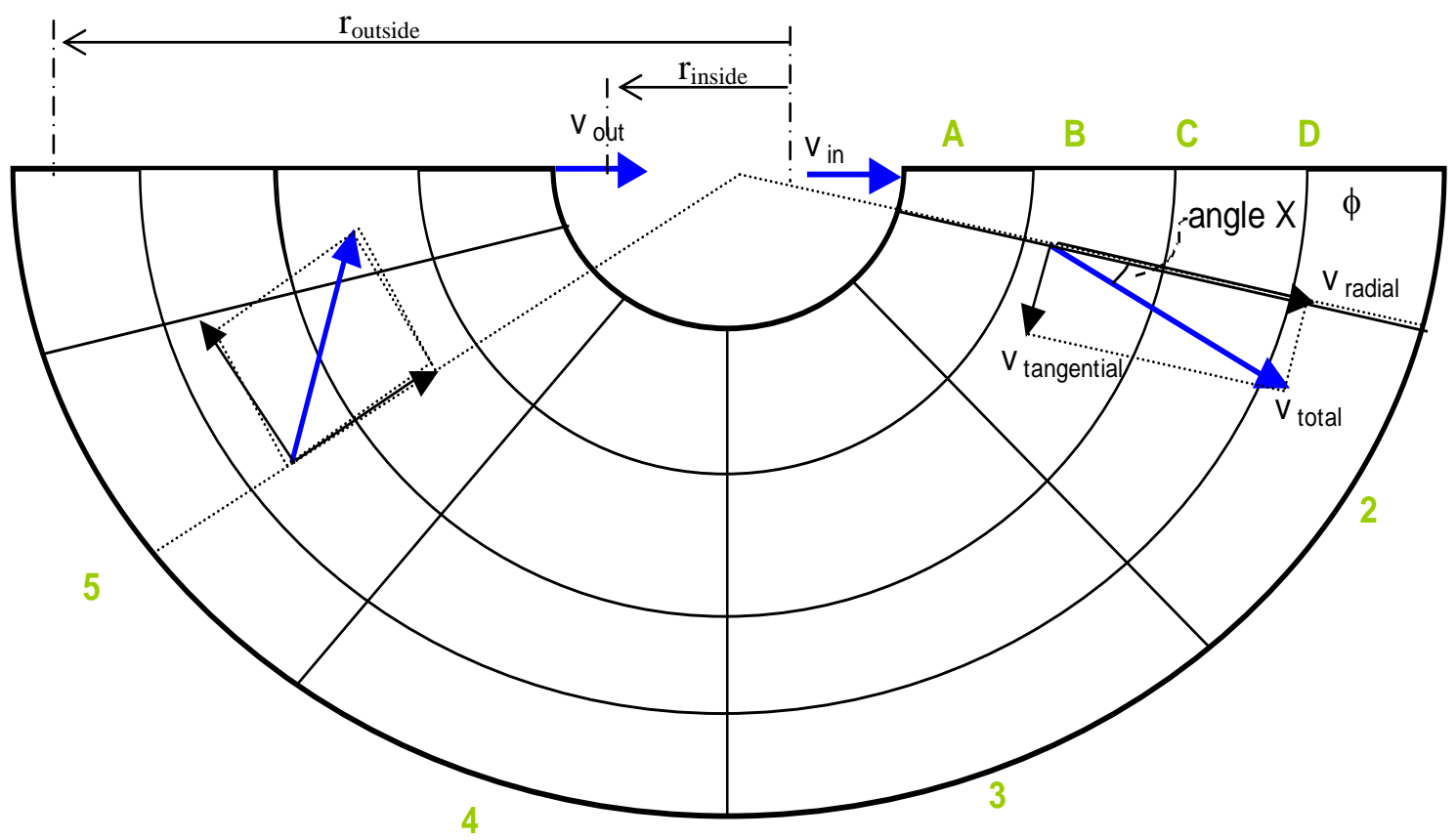

Figure 3.7 Scheme of the model to calculate flow, heat transfer and pressure drop. The definition of the grid is in cylindrical coordinates. The flow enters the grid in radial direction in cell A1 and leaves the grid at cell A6.

The pressure loss for a segment is in general:

$\Delta p=f \frac{L \dot{M}^{2}}{\rho D_{h}}=f \frac{L \rho \dot{V}^{2}}{D_{h}}$

where the friction factor $\mathrm{f}$ is equal to $f=\frac{64}{\mathrm{Re}}$ for a laminar flow. For a sandwich plate the pressure loss is a factor four higher than for a flat plate (Hewitt, 2002, chapter 3.7.3).

The local and total thermal power and temperature change of the medium is calculated in combination with a fixed temperature of the surrounding:

$q_{r, \phi}=h_{r, \phi} A_{r . \phi}\left(T_{r, \phi}-T_{\text {surrounding }}\right)$

For a continuous system, the local temperature is equal the sum of the mixing flows and the heat transfer to the surrounding:

$T_{r, \phi}={ }^{q_{r, \phi}} \hat{V}_{r, \phi} \rho c p+\frac{V_{r-1 \rightarrow r, \phi}}{V_{r, \phi}} T_{r-1, \phi}+\frac{V_{r, \phi-1 \rightarrow \phi}}{V_{r, \phi}} T_{r, \phi-1}$

The results of the model calculations are compared with the results of the experiments in section 4. 


\section{Heat transfer experiments and results}

\subsection{Visualisation of flow distribution}

To visualize the flow in the sandwich plate a small Plexiglas heat exchanger was built. Experiments were carried out with a constant flow between the plates. On a certain moment 0.1 $\mathrm{ml}$ concentrated colouring agent (methylene blue) was injected in the flow. A digital camera recorded the displacement of the colouring agent. The influence of the flow velocity, the entrance area of the flow, the use and orientation of the wire mesh, the number, the length and the position of the flow directors on the flow distribution was evaluated. In this way of experimenting, a good overview of the flow distributions was obtained and could be compared with the results of the simulations. As an alternative for this visual method of interpretation of the measurement the dimensionless value $\zeta$, the 'volume utilisation factor', is introduced. The factor is defined as the ratio of the real accommodation time, which is the same as the shortcircuit time, and the average theoretical accommodation time.

$$
\zeta=\frac{t_{\text {accom,real }}}{t_{\text {accomt,heoretical }}}=\frac{t_{\text {short-circuit }}}{\left(\frac{V_{\text {heat exchanger }}}{V}\right)}
$$

An ideal uniform flow occurs in the case $\zeta=1$. When $\zeta<<1$, the medium flows with high velocity directly from entry to exit meaning that over a large area of the heat exchanger the flow velocity is very low or zero, resulting in poor heat transfer. The risk of fouling is also much higher in this situation. In Figure 4.1 and Figure 4.2 the difference between a flow with and without wire mesh is shown. In the case there is no mesh, the pressure drop is lower, so the entrance velocity is higher and this results in a wider distribution of the flow over the total surface.

A design with a wire mesh and four flow distributors, two near the entry and two near the exit, performs with a $\zeta= \pm 0.75$ much better than a system without distributors, with a value of $\zeta<0.25$ (see Figure 4.3 and Figur 4.4). The influence of the distributors on the pressure drop is not measured, only simulated.

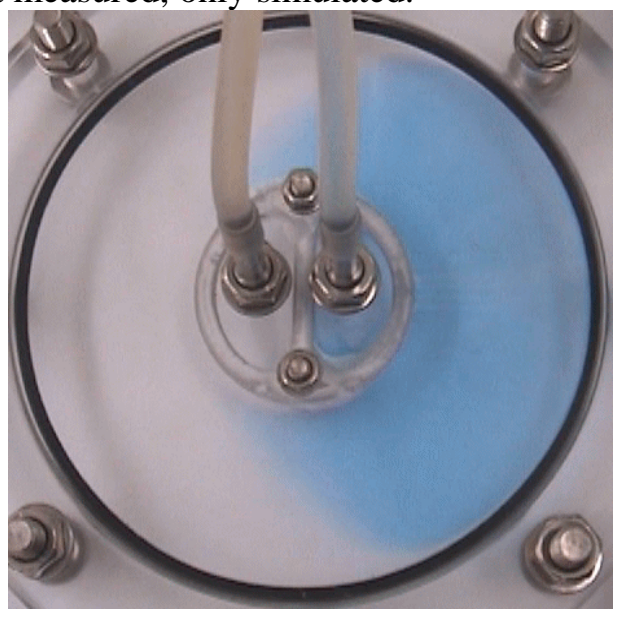

Figure 4.1 Flow pattern at $t=1.4 \mathrm{sec}$ without wire mesh. The short-circuit time is 1.6 seconds $(\zeta \cong 0.3)$.

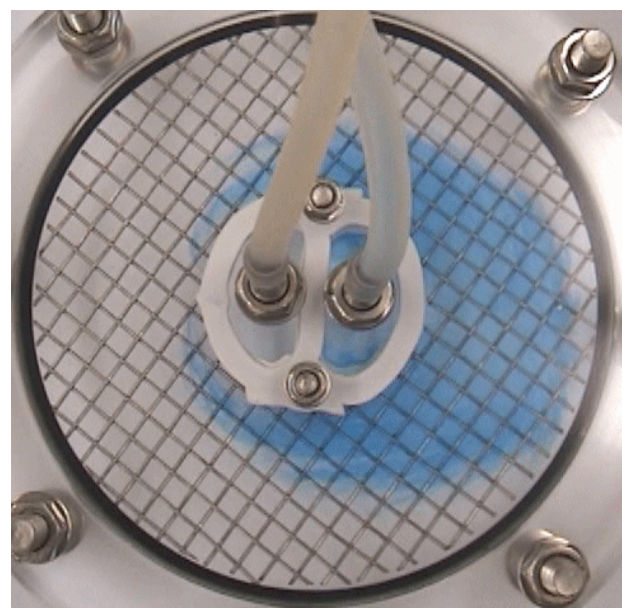

Figure 4.2 Flow pattern at $t=1.4 \mathrm{sec}$ with wire mesh under an angle of $45^{\circ}$. The short-circuit time is 1.2 seconds $\zeta \cong 0.27$ ). 


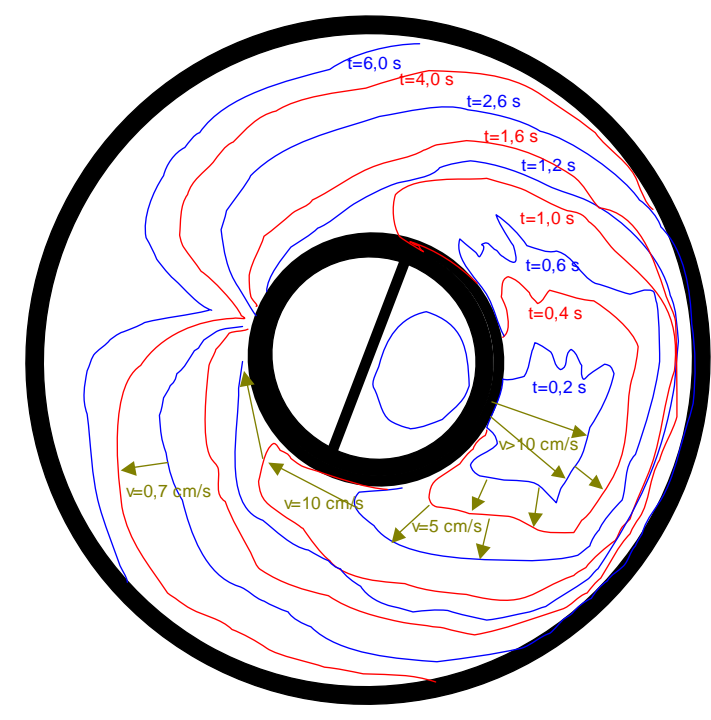

Figure 4.3 Image analysis of the measured flow pattern without flow distributor. The short-circuit time is 1.2 seconds ( $\zeta \cong 0.25$ ), with large differences in velocity.

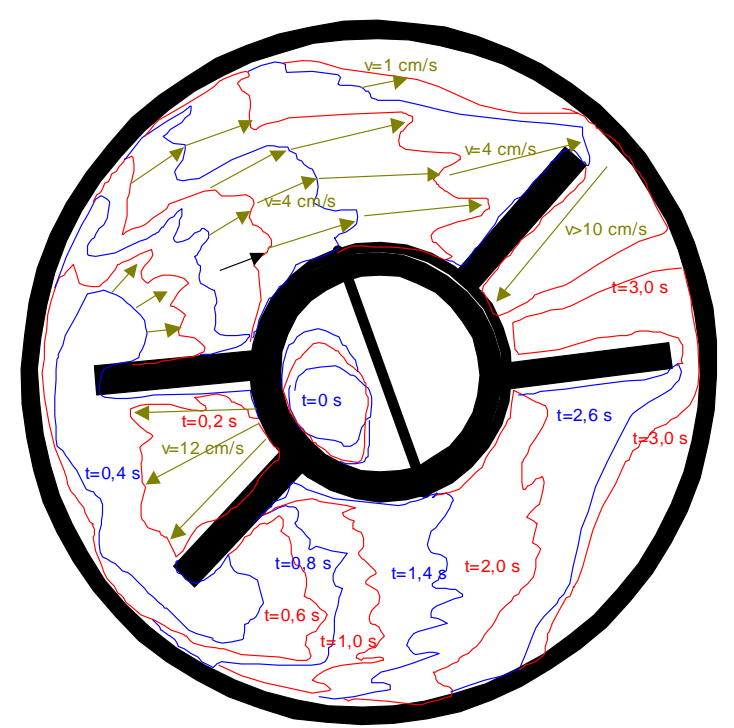

Figure 4.4 Image analysis of the measured flow pattern with four flow distributors. The short-circuit time is \pm 3 seconds $(\zeta \cong 0.75$ ). The flow distribution is quite good.

By describing the front of the blue coloured medium for different time steps in one figure, the local velocity en direction can be determined. The maximum speed was just after entry, before the exit and between the outside wall and the flow conductors. The speed had a minimum near the outside wall at two-third of the total flow distance. The front was not smooth caused by continuously mixing the flow due to the wire mesh.

\subsection{Heat transfer measurement}

A vacuum test-rig was used to determine the rate of convective heat transfer between a heat transport fluid and a heat exchanger under dynamic conditions described previously by De Boer (2005). A single sandwich plate heat exchanger (outside diameter is $0.35 \mathrm{~m}$ ) was placed inside the vacuum vessel and the flow and the temperature at the inlet and outlet of the heat transfer fluid was monitored. The vacuum surrounding of the heat exchanger is used to prevent heat losses to the surroundings. There is only thermal contact between heat exchanger and the wall through poorly conducting polyamide belts used for fixing the heat exchanger and Teflon tubes for connecting the thermal fluid.

The measurements start with a continuous flow and a stable temperature. By switching the flow from a hot to a cold reservoir (or vice versa), a stepwise temperature change is applied at the inlet of the heat exchanger. The difference between the rate of heating or cooling at the entrance and exit is a measure for the amount of heat transferred by the heat exchanger. In cases where the thermal conduction resistance in the heat exchanger is much smaller as the resistance for convection, (Biot number $<<1$ ) an average hA value can be calculated. The hA value, the product of the heat transfer coefficient $h$ and the heat transfer area $A$, is a common value for performance of a heat exchanger.

A sandwich plate heat exchanger is chosen as shown in figure 2a with an outside diameter of $0.35 \mathrm{~m}$ and an inside diameter of $0.04 \mathrm{~m}$ (Figure 3.7) and a wire diameter of $1 \mathrm{~mm}$ with a pitch of $5 \mathrm{~mm}$. In Figure 4.5 the hA value is given for heating and cooling this heat exchanger with thermal oil Calflo LT as heat transport medium. A fixed temperature step of 50 degrees is applied with variable flow conditions in the range of 1 to 4 litres a minute. The minimum heat 
transfer design value for the HTCWP is also given. The results of these measurements were also used to compare with the model described in section 3.2. Also with a flow of $4 \mathrm{l} / \mathrm{min}$, the velocity of the oil is quite low, which results in a disturbed laminar flow.

The calculated average hA is the sum of the product of local heat transfer $h_{i}$ and heat transfer area $A_{i}$ for $i$ segments of the grid. The local heat transfer coefficient varies in the range of 550 to $1550 \mathrm{~W} / \mathrm{m}^{2} \mathrm{~K}$. The calculated pressure drop is $\pm 30 \mathrm{mbar}$. The maximum thermal power is equal to $3.6 \mathrm{~kW}$ (see Figure 4.6). Especially for a low flow of 2 litres per minute, there is a good correlation between model and experiment. The same plate heat exchanger was also tested with water as heat transport medium (Figure 4.7). The hA value for a water filled heat exchanger is more than three times better than thermal oil as a medium.

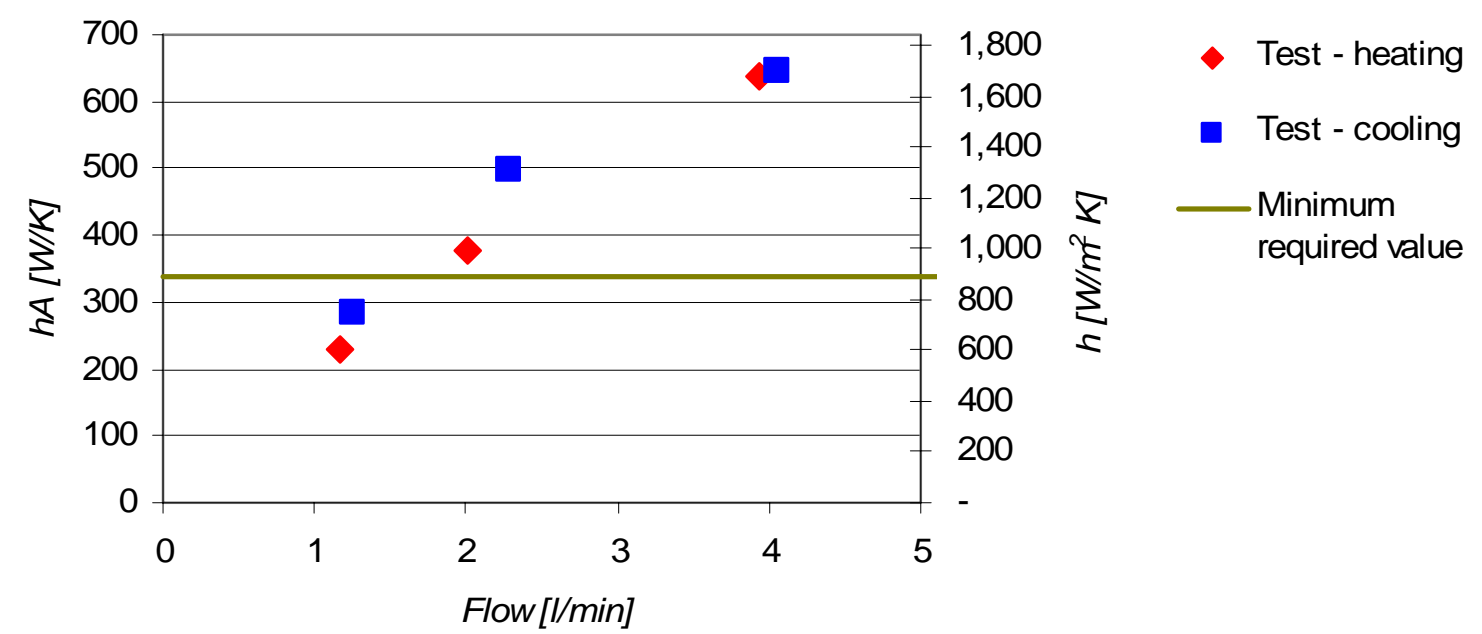

Figure 4.5 Measurement of hA-value (coefficient of overall heat transfer $x$ heat transfer area) as a function of the flow. Medium is thermal oil Calflo LT with a temperature between $40-90^{\circ} \mathrm{C}$. Heat transfer area of sandwich plate heat exchanger $=0.4 \mathrm{~m}^{2}$.

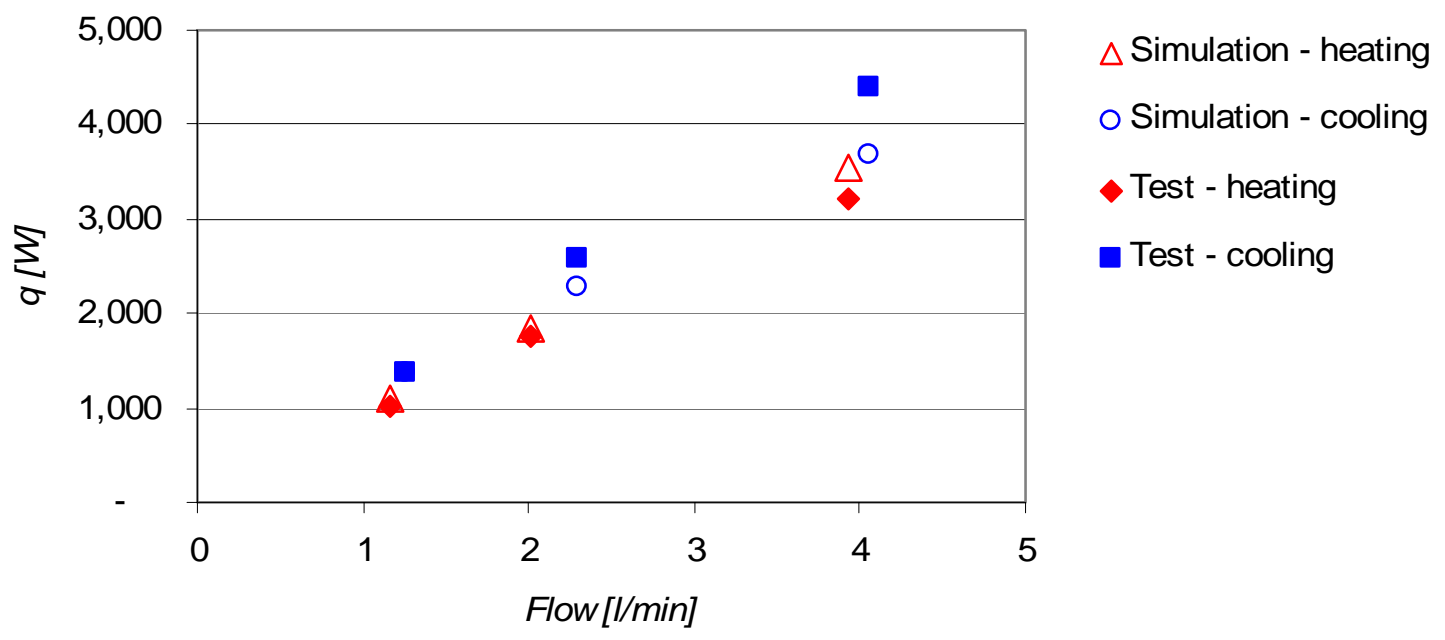

Figure 4.6 Comparison of the measured values and the simulated values for the sandwich plate of thermal power just after switching from 40 to $90^{\circ} \mathrm{C}$ (heating) and 90 to $40^{\circ} \mathrm{C}$ (cooling). The medium is thermal oil Calflo LT, measurement in the vacuum vessel. 


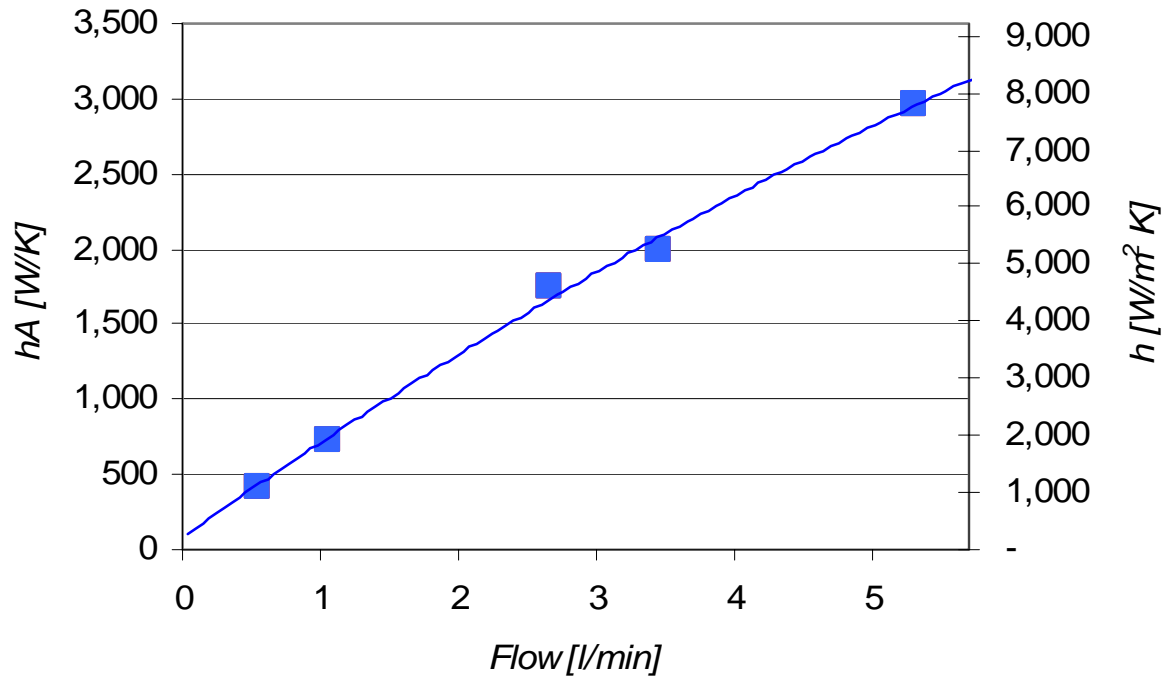

Test - cooling

Figure 4.7 Measurement of hA-values as function of the flow. Medium is water with a temperature between $90-40^{\circ} \mathrm{C}$. Heat transfer area of the sandwich plate heat exchanger is $0.4 \mathrm{~m}^{2}$ 


\section{Sandwich plate heat exchanger applications}

Excellent heat transfer and other advantageous properties as low weight and simple construction open a range of possible applications for the sandwich plates. It can be used for solid sorption heat pumps with a heat transfer fluid inside the sandwich plate and a sorbent on the other side. The addition of metal foam or fins enhances the heat transfer from the flat plat to the solid sorbent.

In the collector of solar hot water systems, a sandwich plate can replace the copper flat plate with small tubes. This results in a stiffer construction and a more equally distributed heat uptake. The application of the sandwich plate in a combined photovoltaic and thermal system is also possible.

Another application is as heat exchanger for small-scale ammonia-water absorption chillers for residential and small commercial applications. Jacked tank systems can be constructed of the sandwich plate, which result in a double wall system. Finally, a wide range of flat panel radiators can be constructed for buildings to be applied in ceilings or on walls. 


\section{Conclusions}

The presented sandwich plate, a brazed structure of two thin plates with a wire mesh in between, is well suited for use as heat exchanger in chemical heat pumps. Especially for this kind of heat exchangers, high demands are requested as to thermal stress resistance. With the right choice of plate thickness, wire diameter and pitch, a heat exchanger can be constructed for a lifetime of 100.000 stress cycles. It remains to be seen if the thermal mass fulfils all requirements of a HTCWP system.

With a combination of experiments and calculations an optimised design for flow distribution is found for the circular sandwich plate heat exchanger. The role of flow distributors is important for a good utilisation of the heat transfer area. The method of comparing the short-circuit time with the average theoretical accommodation time is a good way to compare the different alternatives of flow distributions.

A simple heat transfer model leads to a good understanding of local parameters as flow velocity, local heat transfer and pressure drop. The results of the model calculations are in good agreement with the experimentally determined average heat transfer of the sandwich plate heat exchanger.

The aspect of fouling was underexposed in this study. Till the completion of a study of the fouling aspect of a sandwich plate heat exchanger, the performance of this heat exchanger is only guaranteed with clean media. Additional experiments for the use of two-phase systems like condensing steam in the sandwich plate heat exchanger are initiated. 


\section{References}

[1] Alfa Laval, http://www.alfalaval.com.

[2] ASME Boiler and Pressure Vessel Code, Section II, Materials, Part D Properties, 2001a Edition

[3] ASME Boiler and Pressure Vessel Code, Section III, Rules for Construction of Nuclear Power Plant Components, Division 1, Subsection NB and NC; 1995 Edition

[4] ASME Boiler and Pressure Vessel Code, Section III, Rules for Construction of Nuclear Power Plant Components, Division 1, Appendices, 2001b Edition

[5] Barsom J.J.M. and Rolfe, S.T., 1999, Fracture \& Fatigue Control in Structures, Applications of Fracture Mechanics, Third Edition, American Society for Testing \& Materials.

[6] Boer, de R., Smeding, S.F., et al., 2005, Development and testing of a sorbent filled heat exchanger for use in compact solid sorption cooling systems, International Sorption Heat Pump Conference; Denver, ISHPC-068-2005.

[7] Haije, W.G., Veldhuis, J.B.J. et al., 2002, Solid sorption based heat transformers for application in industrial processes: a techno-economic evaluation, International Sorption Heat Pump Conference, Shanghai, China, 469-472.

[8] Hewitt, G.F., 2002, Heat Exchanger Design Handbook 2002 (HEDH) Volume 3, Part 3. Thermal and Hydraulic Design of Heat Exchangers.

[9] Incropera F.P. and Witt D.P., 1990, Fundamentals of Heat and Mass Transfer (3rd edition), Wiley and Sons.

[10] Kohnke, P., 1999, ANalysis SYStem, Theory Reference, Release 5.6, ANSYS, Inc.

[11] Lambert, M.A. and Jones B.J., 2005, Review of regenerative adsorption heat pumps, Journal of Thermophysics and Heat Transfer, 19, 471-485.

[12] Lu, T. J., Valdevit, L., et al., 2005, Active cooling by metallic sandwich structures with periodic cores, Progress in Materials Science, 50, 789-815.

[13] Vahterus, http://www.vahterus.com. 